\title{
Prospective visible laser active media based on disordered fluorite-type structure crystals
}

\author{
Oleg Morozov ${ }^{1}$, Sergey Kuznetsov², Vasiliy Konyushkin ${ }^{2}$, and Andrey Nakladov ${ }^{2}$, \\ Alexey Nizamitdinov ${ }^{1}$, Pavel Fedorov ${ }^{2}$ and Vadim Semashko ${ }^{1}$ \\ ${ }^{1}$ Kazan Federal University, 420008 Kazan, Russia \\ ${ }^{2}$ Prokhorov General Physics Institute of the Russian Academy of Sciences, 119991 Moscow, Russia
}

\begin{abstract}
The synthesis conditions and the results of spectral-kinetic studies of disordered crystals series $\mathrm{CaF}_{2}-\mathrm{LaF}_{3}-\mathrm{PrF}_{3}$ with variable chemical composition are presented. The prospects of using these crystals as active media for the visible spectral range DPSS laser pumped by InGaN (GaN) laser diodes and operating on $4 \mathrm{f}-4 \mathrm{f}$ transitions of $\mathrm{Pr}^{3+}$ ions are discussed.
\end{abstract}

The development of biosensor and biomedical applications causes a steady interest in visible DPSS (diode pumped solid-state) lasers [1]. Visible range laser action is realized at $4 \mathrm{f}-4 \mathrm{f}$ transitions of $\mathrm{Pr}^{3+}, \mathrm{Tb}^{3+}, \mathrm{Sm}^{3+}, \mathrm{Eu}^{3+}$ ions in crystals and glasses pumped by $\mathrm{InGaN}(\mathrm{GaN})$ laser diodes (LD) [2]. The most promising of active media are the $\operatorname{Pr}^{3+}$ ion doped fluoride crystals demonstrating highest output properties [3-5]. However, the expansion of these DPSS lasers is limited by a narrow absorption spectral line width of dopants to compare with the LD emission spectra. It requires the enhanced selection of LD according to central emission wavelength. Using of disordered crystalline matrices can solve this problem.

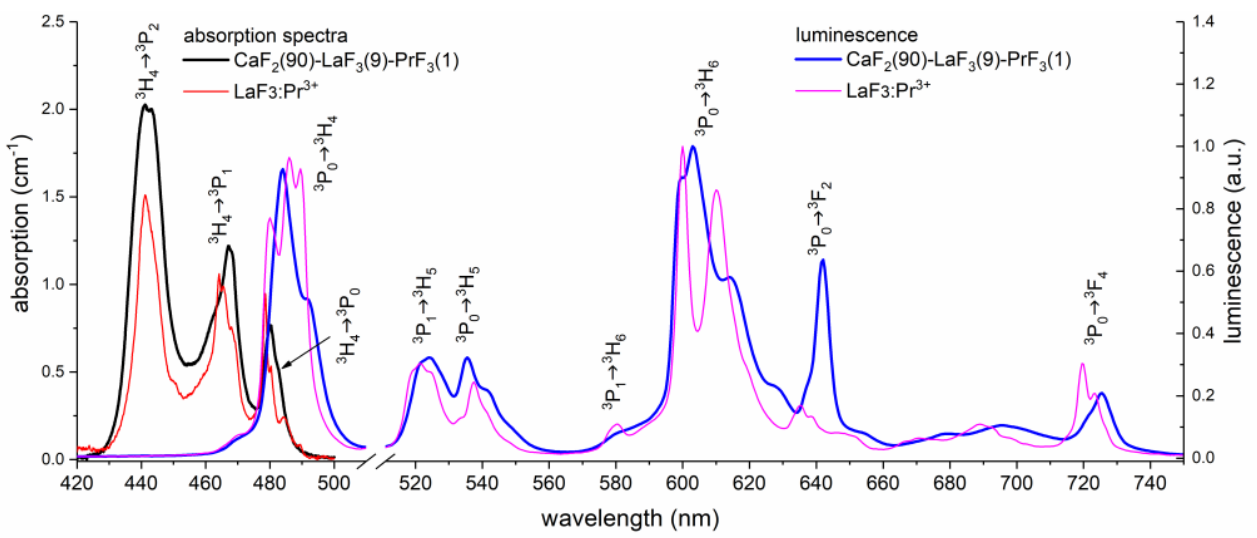

Fig. 1. Absorption and luminescence spectra of $\mathrm{CaF}_{2}(90)-\mathrm{LaF}_{3}(9)-\operatorname{PrF}_{3}(\mathrm{x}=1)$ and $\mathrm{LaF}_{3}: \mathrm{Pr}^{3+}\left(\mathrm{C}_{\mathrm{pr}}=1\right.$ at.\%).

The report provides growing conditions and spectral-kinetic studies of disordered crystals series $\mathrm{CaF}_{2}-\mathrm{LaF}_{3}-\mathrm{PrF}_{3}$ with variable chemical composition. The prospects of using these 
crystals as active media for the visible spectral range DPSS laser pumped by InGaN (GaN) LD are discussed.

Single crystals of $\mathrm{CaF}_{2}(90)-\mathrm{LaF}_{3}(10-\mathrm{x})-\mathrm{PrF}_{3}(\mathrm{x})$ solid solutions $(0.5 \%<\mathrm{x}<8 \%)$ were grown by the Bridgman technique in graphite crucibles in high-purity $\mathrm{Ar}+\mathrm{CF}_{4}$ atmosphere. The obtained crystals have the length of $40 \mathrm{~mm}$ and diameter of $10 \mathrm{~mm}$. Absorption and fluorescence spectra were recorded using the MDR-23 monochromator with attached FEU100 photomultiplier. Fluorescence of the samples was excited by pulsed radiation of the optical parametric oscillator laser system (LT-2215LC) from JV LOTIS TII. The luminescence energy yield (LQY) was studied in the integrating sphere IS200 (Thorlabs). The experimental results at room temperature are presented in Fig. 1 and summarized in table 1 .

Table 1. Effective lifetimes, luminescence energy yield (LEY) and luminescence quantum yield of $\mathrm{Pr}^{3+}$ ions ${ }^{3} \mathrm{P}_{0} \rightarrow{ }^{3} \mathrm{H}_{\mathrm{j}},{ }^{3} \mathrm{~F}_{\mathrm{j}}$ transitions in $\mathrm{CaF}_{2}(90)-\mathrm{LaF}_{3}(10-\mathrm{x})-\mathrm{PrF}_{3}(\mathrm{x})$ disordered crystals.

\begin{tabular}{|l|c|c|c|}
\hline \multicolumn{1}{|c|}{ Sample Composition } & $\tau$, us & LEY,\% & LQY, $\%$ \\
\hline CaF2(90)-LaF3(9.5)-PrF3(0.5) & 38 & $40 \pm 3$ & $95 \pm 4$ \\
\hline CaF2(90)-LaF3(9)-PrF3(1) & 26 & $20 \pm 3$ & $49 \pm 4$ \\
\hline CaF2(90)-LaF3(8.5)-PrF3(1.5) & 19 & $12 \pm 3$ & $29 \pm 4$ \\
\hline $\mathrm{CaF} 2(90)-L a F 3(8)-P r F 3(2)$ & 14 & $7 \pm 1$ & $16 \pm 2$ \\
\hline $\mathrm{CaF} 2(90)-L a F 3(6)-P r F 3(4)$ & 5 & $1 \pm 0.3$ & $2 \pm 0.5$ \\
\hline $\mathrm{CaF} 2(90)-L a F 3(2)-P r F 3(8)$ & 0.9 & $0.1 \pm 0.1$ & $0.2 \pm 0.2$ \\
\hline
\end{tabular}

It was found that the ${ }^{3} \mathrm{H}_{4}{ }^{3} \mathrm{P}_{\mathrm{j}}$ absorption spectrum lines of disordered $\mathrm{CaF}_{2}(90)-\mathrm{LaF}_{3}(10-\mathrm{x})-$ $\mathrm{PrF}_{3}(\mathrm{x})$ crystals are noticeably broader than the similar ones of $\mathrm{LaF}_{3}: \mathrm{Pr}^{3+}$ crystal. For instance, the ${ }^{3} \mathrm{H}_{4}-{ }^{3} \mathrm{P}_{2}$ transition has the absorption bandwidth (FWHM) approximately $7.6 \mathrm{~nm}$ for $\mathrm{LaF}_{3}: \mathrm{Pr}^{3+}$ sample and $10.2 \mathrm{~nm}$ for the $\mathrm{CaF}_{2}(90)-\mathrm{LaF}_{3}(9)-\operatorname{PrF}_{3}(\mathrm{x}=1)$ sample. Thus, following data of table 1 and ref.6, the disordered $\mathrm{CaF}_{2}-\mathrm{LaF}_{3}-\mathrm{PrF}_{3}$ crystals look a promising active media for visible-range DPSS.

The study was done in the frame of the subsidy allocated to KFU for the state assignment in the sphere of scientific activities (3.1156.2017/4.6). V.V. Semashko personally thanks the project 3.6722.2017/8.9 (former 3.5835.2017/6.7)) for the financial support.

\section{References}

1. T. Vo-Dinh, Biomedical Photonics Handbook (CRC Press, Boca Raton, 2003)

2. C. Kränkel, D. T. Marzahl, F. Moglia, G. Huber, P. W. Metz, Las. Photon. Rev., 10, 548 (2006)

3. P. W. Metz, F. Reichert, F. Moglia, S. Müller, D.-T. Marzahl, C. Kränkel, G. Huber, Opt. Lett., 39, 3193 (2014)

4. T. Gün, P. Metz, G. Huber, Opt. Lett., 36, 1002 (2011)

5. S. Luo, X. Yan, Q. Cui, B. Xu, H. Xu, Z. Cai, Opt. Commun., 380, 357 (2016)

6. F. Reichert, F. Moglia, D. T. Marzahl, P. Metz, M. Fechner, N.-O. Hansen, G. Huber, Opt. Express., 20, 20387 (2012) 